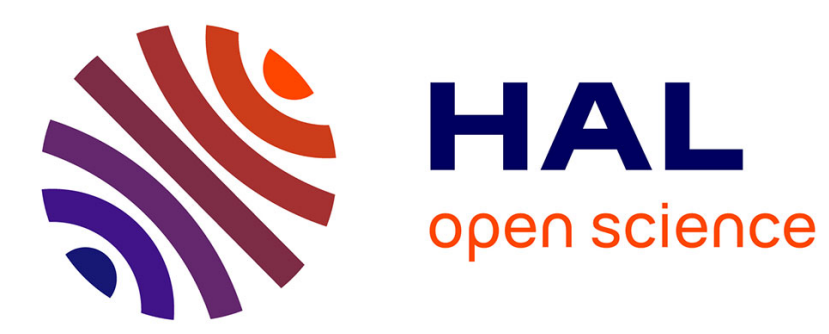

\title{
Development of High Frequency Large Ferrite Toroids for Accelerators
}

\author{
R. Shinde, H. Bhasin, M. Karmarkar
}

\section{To cite this version:}

R. Shinde, H. Bhasin, M. Karmarkar. Development of High Frequency Large Ferrite Toroids for Accelerators. Journal de Physique IV Proceedings, 1997, 07 (C1), pp.C1-149-C1-150. 10.1051/jp4:1997152 . jpa-00255099

\section{HAL Id: jpa-00255099 https://hal.science/jpa-00255099}

Submitted on 1 Jan 1997

HAL is a multi-disciplinary open access archive for the deposit and dissemination of scientific research documents, whether they are published or not. The documents may come from teaching and research institutions in France or abroad, or from public or private research centers.
L'archive ouverte pluridisciplinaire HAL, est destinée au dépôt et à la diffusion de documents scientifiques de niveau recherche, publiés ou non, émanant des établissements d'enseignement et de recherche français ou étrangers, des laboratoires publics ou privés. 


\title{
Development of High Frequency Large Ferrite Toroids for Accelerators
}

\author{
R.S. Shinde, H.K. Bhasin* and M.G. Karmarkar \\ MPS-1, Accelerator, Centre for Advanced Technology, CAT, Indore 452013, India \\ * Winner - Nipphon Electronics Ltd., New Delhi, India
}

\begin{abstract}
Large soft ferrite toroids \& slabs in various $\mathrm{Ni}-\mathrm{Zn}$ compositions were developed for high frequency switching magnets (kickers) \& fast rise time current monitors of $450 \mathrm{MeV}$ Electron Accelerator. The electric \& magnetic properties of large ferrite ring cores were obtained using a special sintering process. These magnetic properties include a high saturation flux density, high initial permeability, low coercivity, large $\mu$ Qf products (at $\widehat{B}: 100 \mathrm{mT}, f=20 \mathrm{MHz}$ ) \& low loss $\mathrm{rf}$ characteristics at high magnetic amplitudes.
\end{abstract}

\section{INTRODUCTION}

Synchrotron radiation facility of CAT consists of $20 \mathrm{MeV}$ microtron, $700 \mathrm{MeV}$ Booster Synchrotron \& $450 \mathrm{MeV}$ storage ring. Very fast kickers are needed in accelerator beam transport lines to transfer the beam into \& out of storage \& damping rings. It is essential to use a kicker magnet having a very short rise time \& a stable switching characteristics[1].

$\mathrm{Ni}-\mathrm{Zn}$-Co ferrites are widely used in hign frequency $(>1 \mathrm{MHz}) \&$ fast pulsed field applications for their unique combination of high flux swing $(\Delta B)$, low coercivity, high electrical resistivity \& low loss of characteristics at high of magnetic amplitudes [1].

$\mathrm{Ni}-\mathrm{Zn}-\mathrm{Co}_{0}$ ferrite slabs \& toroids were developed by sintering at low temperature $\left(1180^{\circ} \mathrm{C}\right)$ with long sintering time $20 \mathrm{hrs}$. Low loss if characteristics were obtained [2].

This paper presents the electric \& magrietic characteristics of large ferrite slabs \& toroids \& high power of measurements.

\section{EXPERIMENTAL}

Toroidal ferrite samples were prepared with a chemical compositions of $\left(\mathrm{Ni}_{35} \mathrm{Zn}_{65}\right) \mathrm{Fe}_{2} \mathrm{O}_{4} \&\left(\mathrm{Ni}_{40}\right.$ $\left.\mathrm{Zn}_{60}\right) \mathrm{Fe}_{2} \mathrm{O}_{4}$ by ceramic techniques. Microstructure of the sintered sampies were observed by SEM. Complex permeability $\left(\mu^{\prime}, \mu^{\prime \prime}\right)$ \& loss factor as a function of frequency $(1-100 \mathrm{MHz}$ ) were measured by RF impedance analyser. Fast pulse B-H measurements \& core losses at high magnetic amplitudes were carried out using a high voltage $(6 \mathrm{KV})$ testing fixture constructed inhouse for this purpose [3].

\section{PULSE MEASUREMENTS \& RESULTS}

We made magnetic hysteresis loop measurements with a pulse core tester in addition to the measurements done at $60 \mathrm{~Hz}$. Fig. 1 shows variation of the flux with field obtained with a pulse magnetizer. Energy loss of the core is determined by integrating the product of the voltage \& current for the pulse duration. We found this value varies widely depending on the rise time of the pulse, bias field strength \& other experimental conditions. Complex permeability spectrum $\left(\mu^{\prime}, \mu^{\prime \prime}\right)$ of a NiZnCo ferrite system is shown in fig. 2. It is observed that there are very low losses in low frequency range $(25 \mathrm{MHz})$. 
Magnetic permeability $(\mu)^{\prime}$ is almost independent of frequency within application frequency ranges from 0.5 to $60 \mathrm{MHz}$. This suppresses the loss contributions from gyromagnetic \& dielectric influences. These are desirable characteristics of ferrites useful in high speed kickers ( $30 \mathrm{~ns}$ rise time) of Accelerators.

RF field dependence of $\mathrm{Ni}-\mathrm{Zn}-\mathrm{Co}$ ferrite toroids at high magnetic amplitudes (B:100 mT, 20 $\mathrm{MHz}$ ) is studied and shown in fig. 3. It is observed the RF losses increases with Brf \& further becomes unstable at high if voltages. This phenomenon is high power instability. At low if levels, non linearity in ferrites is weak \& loss of the ferrite is caused mainly by relaxation between uniform mode \& lattice. At high power levels non linearity increases in the ferrites, \& the coupling between the uniform mode \& the spin wave modes becomes stronger [3].

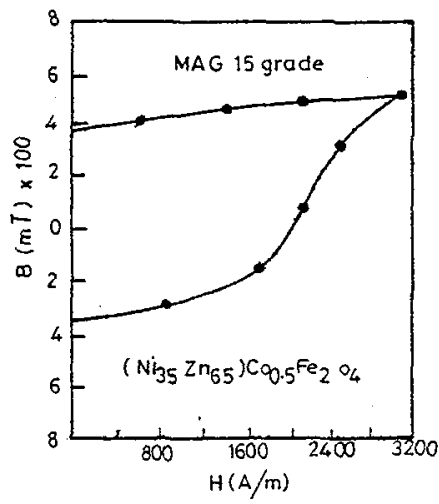

Fig.1. Variation of $B(m T)$ as a function of applied field for $\mathrm{Ni}-\mathrm{Zn}$-Co ferrites

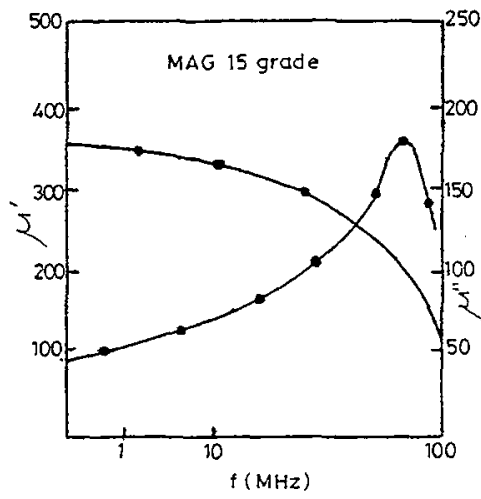

Fig.2. Complex $\mu$ as a function of frequency $(\mathrm{MHz})$

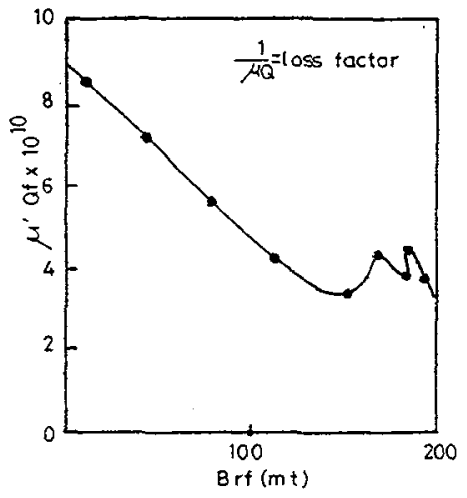

Fig.3. Plot of $\mu \mathrm{Qf}$ against $B_{\pi f}$

\section{CONCLUSIONS}

A pulse test stand was constructed \& the pulse response of Ni-Zn-Co ferrite materials was examined. $\mathrm{Ni}-Z n-\mathrm{Co}_{0}$ (MAG - 15 grade) have low losses at high $\mathrm{if}$ magnetic fields \& larger pulse permeability under dynamic conditions. Also they have small non linear effect over the kicker's operating frequency range. Ni-Zn-Co (Grade MAG-15) material was chosen for 30 ns, switching kickers \& fast current monitors. Kickers \& current monitors have been developed using MAG-15 grade slabs (120 x $100 \times 20$ $\mathrm{mm}) \&$ toroids $(120 \mathrm{~mm}$ OD $\times 90 \mathrm{~mm}$ iD $\times 20 \mathrm{~mm}$ Ht).. These magnetic devices are working entirely satisfactorily during accelerator operations since a year \& found most efficient \& reliable.

\section{Acknowledgement}

The authors are indebted to Dr. D.D. Bhawalkar, Director, CAT for helpful discussions \& encouragement. It is a pleasure to thank Mr. Yadav, Shiny \& Murthy for their technical assistance. Also we are grateful to Shri. Vedprakash for technicai discussion of measuring systems.

\section{References:}

1. H. Yokoyama, Y. Hirose \& S. Chiba, ICF (1970), P. 233-35

2. R.S. Shinde \& S.S. Ramamurthi, " High frequency ferrites for Accelerators ", ICF-6 (1996), P. 1195-97

3. T. Hikosaka, M. Miyamoto \& T. Morita, "Evaluation method for high frequency magnetic properties \& core loss of large ferromagnetic cores". The $9^{\text {th }}$ Sym. on Accel-Sci \& Technology Tsukuba, Japan 1993. 